\title{
Aplikasi Interaktif Pengenalan Huruf Hijaiyah Sebagai Media Pembelajaran Anak
}

\author{
Linda Azka Dini ${ }^{1}$, Sri Muryani ${ }^{2}$, Khoirun Nisa ${ }^{3 *}$ \\ ${ }^{1}$ Prodi Sistem Informasi Akuntansi, Universitas Bina Sarana Informatika, Jakarta Barat, Indonesia \\ ${ }^{2}$ Program Studi Teknik Informatika, STMIK Nusa Mandiri, Jakarta Selatan, Indonesia \\ ${ }^{3}$ Program Studi Sistem Informasi, STMIK Nusa Mandiri, Jakarta Selatan, Indonesia \\ Email: ${ }^{1}$ lindaazka99@gmail.com, ${ }^{2}$ sri.smy@nusamandiri.ac.id, ${ }^{3 *}$ khoirun.khn@nusamandiri.ac.id
}

\begin{abstract}
Abstrak
Belajar Membaca AlQuran merupakan hal penting bagi umat Islam, pembelajaran AlQuran diberikan sedini mungkin kepada anak-anak dengan tujuan agar lebih cepat mengaji AlQuran dengan tartil sekaligus untuk menanamkan nilai-nilai pendidikan agama Islam pada diri anak tersebut. Sebelum ke tahap membaca AlQuran, yang pertama dipelajari adalah pengenalan hurufhuruf hijaiyah. Mulai dari pelafalannya dan cara membedakan bentuknya yang berjumlah 30 huruf. Seiring berkembangnya teknologi jaman sekarang ini, minat pembelajaran dengan metode buku sering membuat anak-anak jenuh. Sehingga peneliti menyadari betapa pentingnya memperkenalkan huruf-huruf hijaiyah kepada anak-anak dengan aplikasi interaktif yang menyenangkan. Aplikasi interaktif ini diharapkan memudahkan anak-anak dalam belajar mengenali huruf hijaiyah Pengenalannya menggunakan animasi audio, visual, serta games yang diharapkan lebih efektif dan efesien dari pada metode pembelajaran menggunakan buku. Diharapkan anak-anak lebih termotivasi lagi dalam belajar mengenali huruf-huruf hijaiyah . Berdasarkan hasil pengujian aplikasi interaktif pengenalan huruf hijaiyah untuk anak-anak menyatakan bahwa aplikasi ini dapat berjalan baik pada komputer dan banyak anak yang menyukainya.
\end{abstract}

Kata Kunci: Aplikasi, Interaktif, Aplikasi Interaktif, Multimedia, Hijaiyah

\begin{abstract}
Learning to Read the Koran is important for Muslims, learning the Koran is given as early as possible to children with the aim to more quickly study the Koran with tartil as well as to instill the values of Islamic religious education in the child. Before going to the Koran reading stage, the first thing to learn is the introduction of hijaiyah letters. Starting from the pronunciation and how to distinguish the forms, amounting to 30 letters. As the development of technology today, the interest in learning by the book method often makes children bored. So that researchers realize how important it is to introduce hijaiyah letters to children with a fun interactive application. This interactive application is expected to make it easier for children to learn to recognize hijaiyah letters. Its introduction uses audio animation, visuals, and games which are expected to be more effective and efficient than learning methods using books. It is hoped that children will be even more motivated in learning to recognize hijaiyah letters. Based on the results of interactive application testing the introduction of hijaiyah letters for children states that this application can run well on computers and many children love it..
\end{abstract}

Keywords: Applications, Interactive, Interactive Applications, Multimedia, Hijaiyah

\section{PENDAHULUAN}

Komputer saat ini sudah berperan aktif dalam dunia pendidikan. Melalui komputer bisa disediakan sarana belajar yang interaktif dan menyenangkan. Pembelajaran dengan pemanfaatan teknologi dapat dipadukan dengan adanya unsur permainan yang interaktif, sehingga merupakan suatu metode pembelajaran yang menyenangkan bagi anakanak untuk belajar [1]. Belajar membaca Al-Qur'an merupakan hal penting bagi umat Islam, terutama bagi anakanak usia dini. Pembelajaran Al-Qur'an sangat penting bertujuan untuk menanamkan nilai-nilai pendidikan Islam pada diri anak tersebut. Pada saat ini kegiatan pembelajaran Al-Qur'an banyak dilakukan oleh lembaga sekolah maupun lembaga diluar sekolah. Namun Sebelum anak dapat membaca Al-Qur'an, anak harus belajar mengenal huruf-huruf hijaiyah terlebih dahulu. Dalam penelitian ini dibangun sebuah alat belajar yang menarik dan interaktif, yang kali ini akan terfokus pada pembelajaran huruf hijaiyah. Dengan adanya aplikasi interaktif pengenalan huruf hijaiyah diharapkan anak-anak lebih bersemangat dan termotivasi dalam belajar. Suasana belajar lebih menyenangkan dan mudah dipahami.

Pembuatan aplikasi Pembelajaran Interaktif Berbasis Multimedia dibuat menggunakan software Adobe Flash CS5 dan bahasa Action Script. Metodologi penelitian yang digunakan mengadaptasi metodologi pengembangan sistem versi Luther-Sutopo dengan tahapan Concept, Design, Material Collecting, Assembly, Testing dan Distribution. Berdasarkan analisa pengembangan sistem menggunakan metodologi Luther-Sutopo tersebut dihasilkan Aplikasi Pembelajaran Interaktif Berbasis Multimedia yang berisi materi-materi dan soal latihan berdasarkan standar kompentensi kurikulum yang berjalan dengan batasan materi untuk pelajaran IPA kelas VI SD [2] .

Pembuatan aplikasi Komik Interaktif Cerita rakyat Jambi berbasis android menggunakan metode studi literatur, perancangan aplikasi, dan uji coba aplikasi yang telah dibuat juga telah dilakukan. Dari aplikasi yang dibuat, informasi dan cerita-cerita rakyat Jambi dapat disampaikan dengan cara yang lebih menarik, yaitu melalui aplikasi komik interaktif dengan gaya gambar yang unik [3]. Penggunaan media pembelajaran interaktif berbantuan aplikasi I-Spring Presenter dapat meningkat kemampuan berpikir kritis peserta didik pada mata pelajaran PPKn kelas XI di SMK Negeri 14 Garut [4]. 


\section{METODE PENELITIAN}

Metode penelitian yang digunakan pada penelitian ini adalah pengembangan metode Waterfall. Tahapan-tahapan Metode Waterfall adalah sebagai berikut [5] :

1. Requirements analysis and definition

Layanan sistem, kendala, dan tujuan ditetapkan oleh hasil konsultasi dengan pengguna yang kemudian didefinisikan secara rinci dan berfungsi sebagai spesifikasi sistem.

2. System and software design

Tahapan perancangan sistem mengalokasikan kebutuhan-kebutuhan sistem baik perangkat keras maupun perangkat lunak dengan membentuk arsitektur sistem secara keseluruhan. Perancangan perangkat lunak melibatkan identifikasi dan penggambaran abstraksi sistem dasar perangkat lunak dan hubungannya.

3. Implementation and unit testing Pada tahap ini, perancangan perangkat lunak direalisasikan sebagai serangkaian program atau unit program. Pengujian melibatkan verifikasi bahwa setiap unit memenuhi spesifikasinya.

4. Integration and system testing

Unit-unit individu program atau program digabung dan diuji sebagai sebuah sistem lengkap untuk memastikan apakah sesuai dengan kebutuhan perangkat lunak atau tidak. Setelah pengujian, perangkat lunak dapat dikirimkan ke customer

5. Operation and maintenance

Biasanya (walaupun tidak selalu), tahapan ini merupakan tahapan yang paling panjang. Sistem dipasang dan digunakan secara nyata. Maintenance melibatkan pembetulan kesalahan yang tidak ditemukan pada tahapantahapan sebelumnya, meningkatkan implementasi dari unit sistem dan meningkatkan layanan sistem sebagai kebutuhan baru.

\section{ANALISA DAN PEMBAHASAN}

\subsection{Analisa Kebutuhan}

Tampilan pengguna merupakan bentuk tampilan grafis yang berhubungan langsung dengan pengguna (user). Antarmuka pengguna berfungsi untuk menghubungkan antara pengguna dengan sistem operasi, sehingga komputer tersebut bisa digunakan. Maka dari itu tampilan dari aplikasi ini akan dibuat semenarik mungkin, sehingga anak-anak sangat tertarik terhadap aplikasi pembelajaran ini.

1. Materi pembelajaran

Materi pembelajaran yang penulis berikan yaitu meliputi pengenalan huruf hijaiyah dengan tanda bacanya serta mengenali ciri-ciri dari huruf hijaiyah tersebut. Aplikasi ini juga dikemas dengan semenarik mungkin sehingga menambah daya minat anak-anak.

2. Games

Games ini bertujuan untuk mengevaluasi kemampuan para pengguna, dan untuk mengukur sampai batas manakah pembelajaran yang telah dikuasai dari masing-masing pengguna.

3. Musik dan Suara Pendukung

Music dan suara pendukung ini digunakan untuk menambah daya tarik aplikasi ini. Musik dapat menenangkan pikiran seseorang dan alat bantu bagi pengembangan kecerdasan manusia. Dan salah satu jenis musik yang banyak dipakai dalam pengkondisian suasana belajar adalah jenis musik klasik Sehingga aplikasi ini menggunakan Music dan suara pendukung agar lebih menarik dan juga sebagai daya tarik bagi penggunanya.

Analisa kebutuhan non fungsional yaitu berupa perangkat keras dan perangkat lunak, diantaranya adalah:

1. Perangkat Keras (Hardware)

Hardware adalah semua bagian fisik komputer yang berfungsi untuk memberi masukan, mengolah dan menampilkan keluaran, dan digunakan oleh sistem untuk menjalankan perintah yang telah diprogramkan. Berikut merupakan perangkat keras (Hardware) yang digunakan penulis untuk membuat aplikasi interaktif pengenalan huruf hijaiyah yaitu :

a. Komputer

b. Mouse

c. Speaker

d. Keyboard

2. Perangkat Lunak (Software)

Software merupakan beberapa perintah yang dieksekusi oleh mesin komputer dalam mengerjakannya. Secara luas perangkat lunak dapat diartikan sebagai suatu prosedur pengoprasian, dan dapat pula diartikan sebagai segala macam jenis program yang digunakan untuk menoperasikan komputer dan peralatannya. Adapun perangkat lunak yang digunakan untuk pembuatan aplikasi interaktif ini adalah:

a. Miscrosoft Windows 7 Ulitimate(32-bit)

b. Visual Basic 

c. Adobe Photoshop 7
d. Sound Recorder
e. Format Factory

\subsection{Perancangan Storyboard}

Fungsi storyboard adalah menerjemahkan isi skenario secara visual atau penggambaran secara singkat. Dalam pembahasan kali ini akan dijelaskan penggambaran storyboard pada aplikasi interaktif pengenalan huruf hijaiyah.Storyboard Menu Utama.

\begin{tabular}{|c|c|c|}
\hline VISUAL & SKETSA & ALDIO \\
\hline $\begin{array}{l}\text { Dalam frame ini terdapat } \\
\text { empat tombol, yaitu: } \\
\text { "mulai belajar" untuk } \\
\text { pengenalan huruf hijaiyah, } \\
\text { "Games" untuk melakukan } \\
\text { games, "Info Program" } \\
\text { untuk penjelasan tentang } \\
\text { penulis, "Keluar" untuk } \\
\text { keluar dari program. }\end{array}$ & $\begin{array}{l}\text { Judul Aplikasi Interaktif } \\
\text { Mulai Belajar } \\
\text { Games } \\
\text { Info Program } \\
\text { Keluar }\end{array}$ & Salam wav \\
\hline
\end{tabular}

Gambar 1. Storyboard Menu Utama

Dalam stroyboard Menu Utama dapat dilihat pilihan menu yaitu Mulai Belajar, Games, Info Program dan Keluar. Pada saat menu utama ditampilkan, akan terdengar suara ucapan salam.

\begin{tabular}{|c|c|c|c|}
\hline VISEAL & & SkETSA & ACDIO \\
\hline \multirow{5}{*}{ 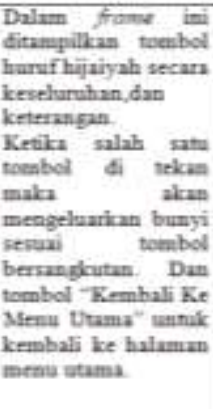 } & \multicolumn{2}{|c|}{ Background } & \multirow{5}{*}{$\begin{array}{l}\text { Suarn } \\
\text { Pengrnalan } \\
\text { Henuf Hijaiylh }\end{array}$} \\
\hline & \multicolumn{2}{|c|}{ Kentbali Ke Mena Utama } & \\
\hline & \multirow[t]{2}{*}{$\begin{array}{l}\text { Keterabeg } \\
\text { an Hunaf } \\
\text { Hijayah }\end{array}$} & Sath Flanuf & \\
\hline & & Horvflatin kgabah & \\
\hline & \multicolumn{2}{|c|}{$\begin{array}{c}\text { Keseluruhan Hiaraf } \\
\text { Hyagah }\end{array}$} & \\
\hline
\end{tabular}

Gambar 2. Storyboard Mulai Belajar

Dalam storyboard Mulai Belajar akan menampilkan huruf hijaiyyah mulai dari alif sampai dengan ya. Saat huruf di klik, akan terdengar suara pengenalan huruf.

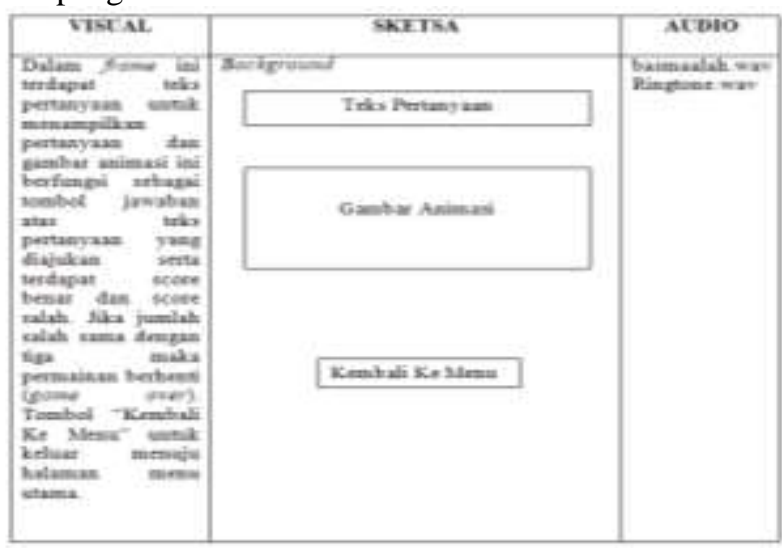

Gambar 3. Storyboard Game

\section{IMPLEMENTASI}

1. Tampilan Menu Utama 
Dalam pilih menu utama ini terdapat empat tombol, yaitu Mulai Belajar, Games, Info Program, dan keluar. Mulai Belajar untuk masuk ke menu pengenalan huruf hijaiyah, Games untuk masuk ke menu games, Info Program untuk penjelasan tentang penulis, dan Keluar untuk keluar dari program.

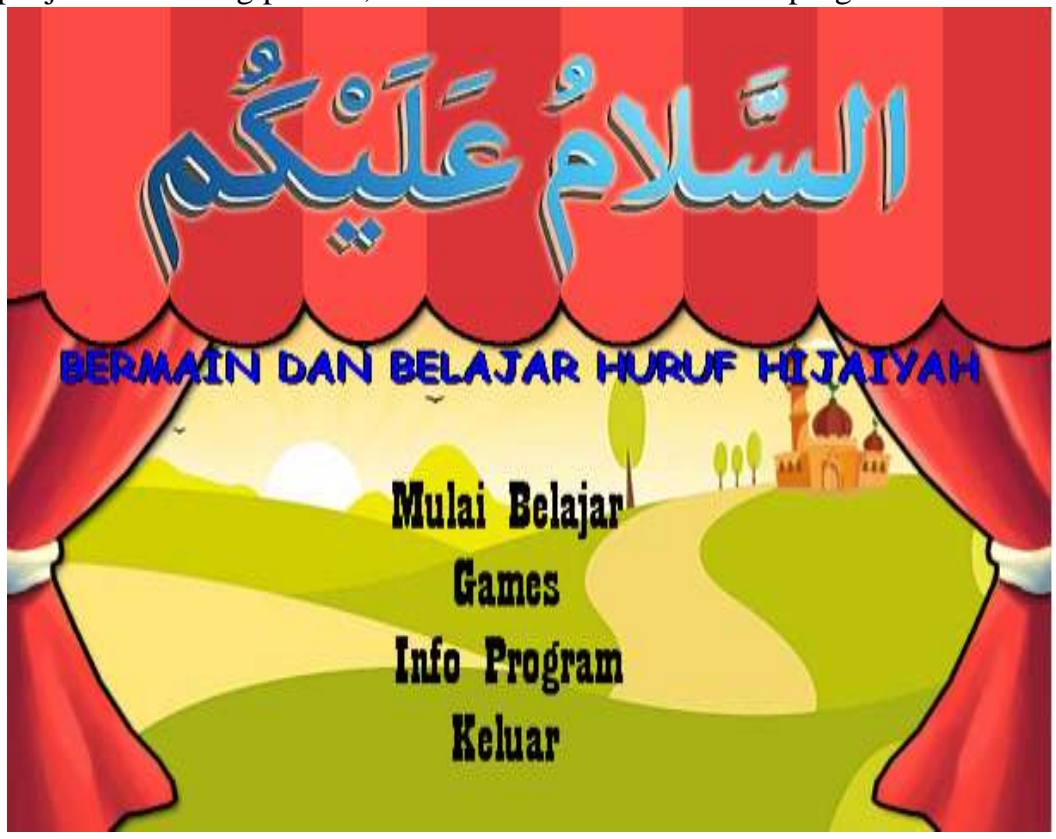

Gambar 4. Tampilan Halaman Menu Utama

2. Tampilan Halaman Mulai Belajar

Dalam Halaman ini ditampilkan tombol huruf hijaiyah secara keseluruhan, dan keterangan. Ketika salah satu tombol di tekan maka akan mengeluarkan bunyi pengenalan huruf hijaiyah sesuai dengan tampilan tombol yang bersangkutan. Dan tombol Kembali Ke Menu Utama untuk kembali ke halaman menu utama.

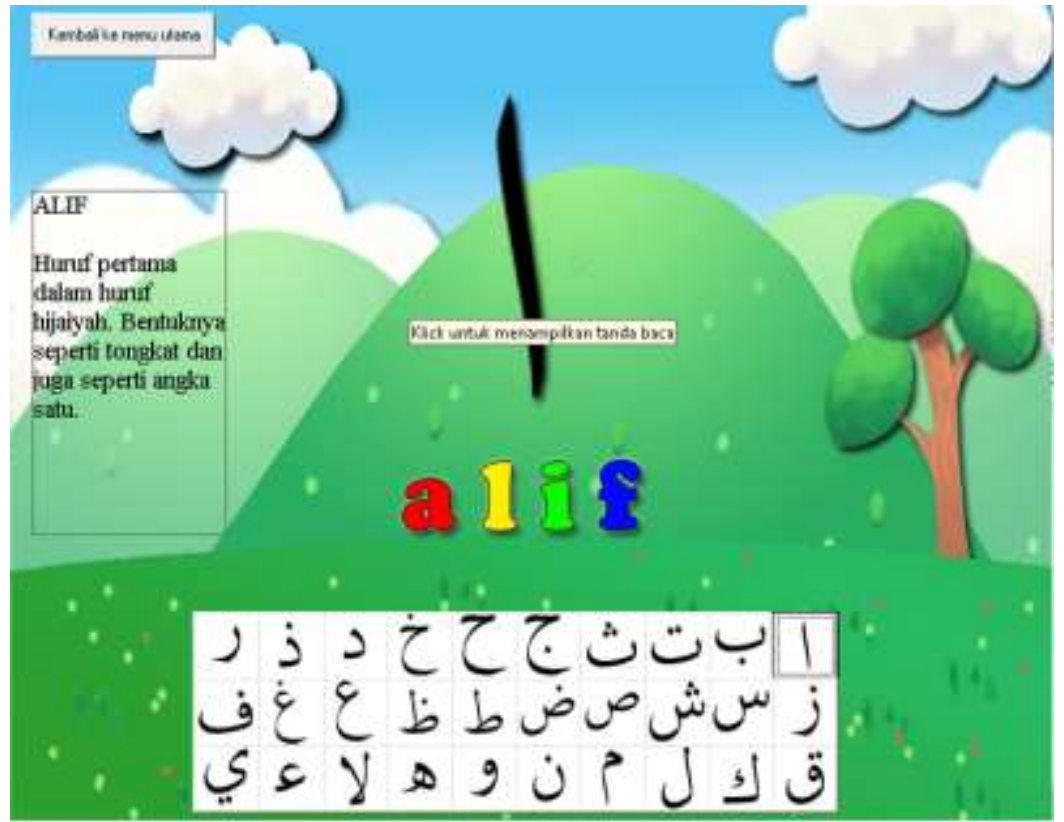

Gambar 5. Tampilan Halaman Mulai Belajar

3. Tampilan Halaman Mulai Belajar Lanjutan

Dalam halaman ini pada satu huruf hijaiyah ada keterangan klick untuk belajar huruf hijaiyah dengan tanda baca. Maka ketika diklick akan keluar halaman pembelajaran huruf hijaiyah dengan tanda baca disertai dengan suara pendukung. Tombol tutup untuk kembali ke halaman mulai belajar. 


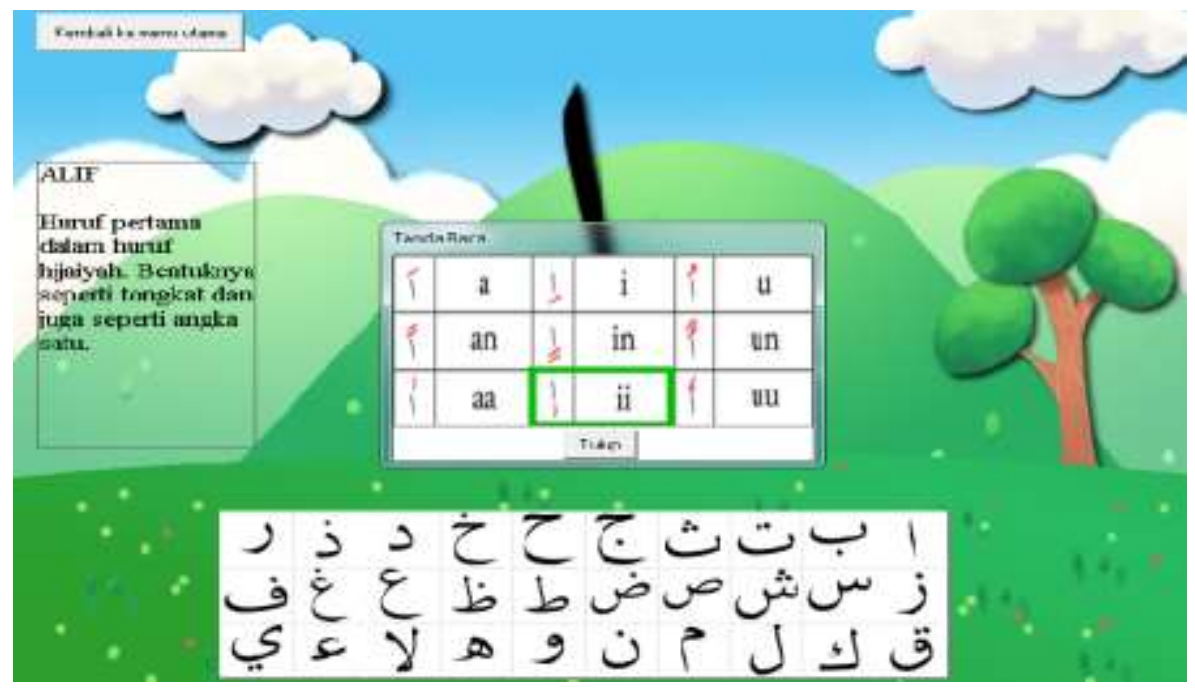

Gambar 6. Tampilan Halaman Mulai Belajar

4. Tampilan Halaman Games

Dalam Halaman ini terdapat Teks Pertanyaan untuk menampilkan pertanyaan. Juga terdapat gambar animasi yang berperan sebagai pemberi jawaban, serta ada score benar dan score salah. Adapun tombol Kembali ke menu untuk keluar menuju halaman menu utama.

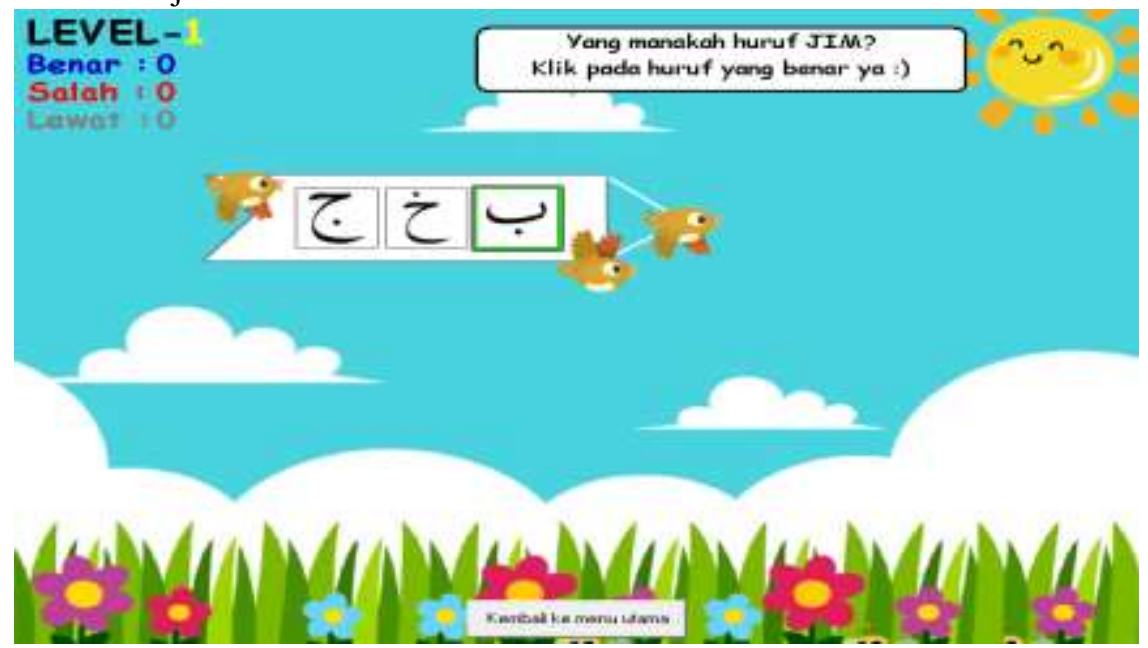

Gambar 7. Tampilan Halaman Games

5. Tampilan Halaman Games Lanjutan

Dalam Halaman ini terdapat teks dan gambar hadiah yang didapatkan user sesuai dengan score yang didapat, dan juga terdapat tombol YA untuk mengulang games, Tombol TIDAK untuk kembali kehalaman menu utama.

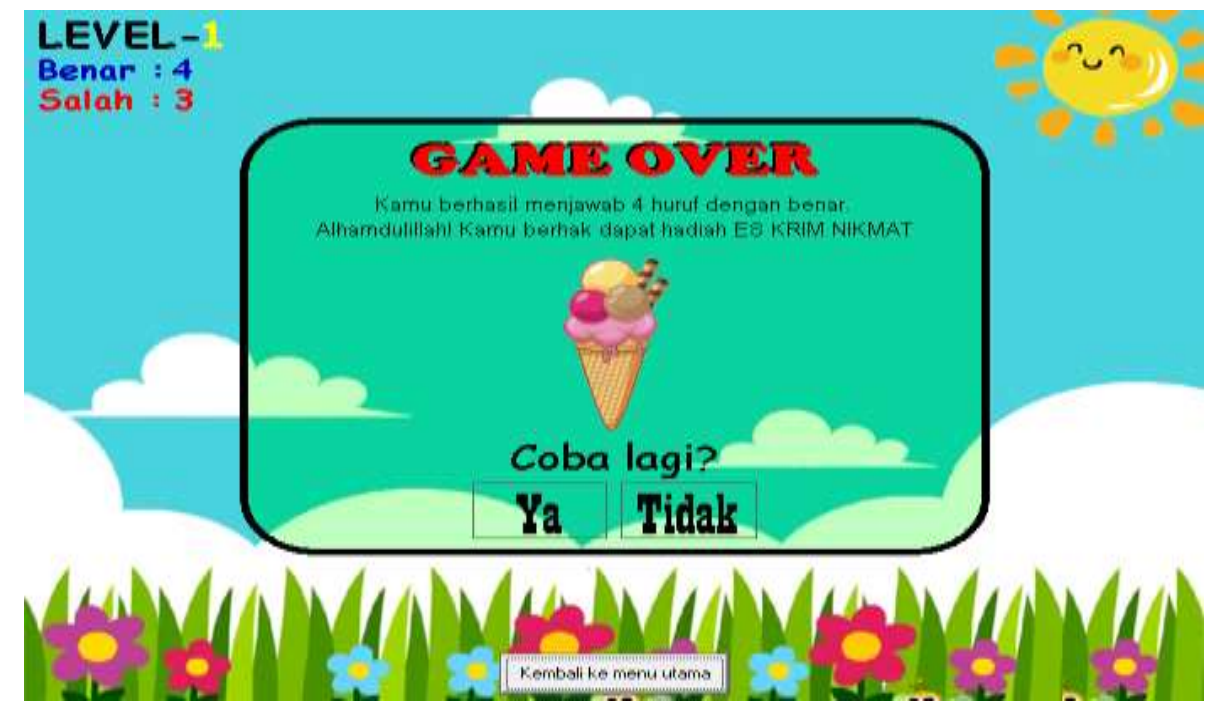

Gambar 8. Tampilan Halaman Games Lanjutan

Linda Azka Dini | http://ejurnal.stmik-budidarma.ac.id/index.php/mib | Page 338 
6. Pengujian Unit

Pengujian unit dilakukan untuk mengetahui fungsionalitas dan cara kerja dari agar sesuai dengan yang dibutuhkan. Berikut adalah pengujian pada Menu Utama.

Tabel 1. Pengujian Menu Utama

\begin{tabular}{|c|c|c|c|}
\hline INPUT & PROSES & OUTPUT & HASIL \\
\hline Loading & $\begin{array}{l}\text { Membuka Aplikasi Huruf } \\
\text { Hijaiyah }\end{array}$ & Menampilkan halaman utama & Berhasil \\
\hline $\begin{array}{l}\text { Pengujian tombol } \\
\text { "Mulai Belajar" }\end{array}$ & $\begin{array}{l}\text { Mengklik tombol "Mulai } \\
\text { Belajar" }\end{array}$ & $\begin{array}{l}\text { Menampilkan form materi pengenalan } \\
\text { dan menutup sementara form menu } \\
\text { utama }\end{array}$ & Berhasil \\
\hline $\begin{array}{l}\text { Pengujian Tombol } \\
\text { "Games" }\end{array}$ & $\begin{array}{l}\text { Mengklik } \\
\text { "Games" }\end{array}$ & $\begin{array}{l}\text { Menampilkan form games dan } \\
\text { menutup sementara menu utama }\end{array}$ & Berhasil \\
\hline $\begin{array}{l}\text { Pengujian Tombol } \\
\text { "Info Program" }\end{array}$ & $\begin{array}{l}\text { Mengklik tombol "Info } \\
\text { Program" }\end{array}$ & Menampilkan form info program & Berhasil \\
\hline $\begin{array}{l}\text { Pengujian Tombol } \\
\text { "Keluar" }\end{array}$ & $\begin{array}{l}\text { Mengklik } \\
\text { "Keluar" }\end{array}$ & Keluar aplikasi & Berhasil \\
\hline
\end{tabular}

\section{KESIMPULAN}

Dalam pembuatan aplikasi interaktif pengenalan huruf hijaiyah ini diharapkan dapat membantu para pengguna terutama anak-anak dalam mengenali huruf-huruf hijaiyah. Esimpulan dari penelitian ini adalah:

1. Aplikasi interaktif pengenalan huruf hijaiyah memberi pengetahuan dalam pengenalan huruf-huruf hijaiyah.

2. Sasaran pengguna aplikasi ini adalah anak-anak.

3. Aplikasi interaktif pengenalan huruf hijaiyah didesain menggunakan aplikasi visual basic .

4. Aplikasi interaktif pengenalan huruf hijaiyah ini dilengkapi games yang menarik.

5. Materi yang disajikan yaitu pengenalan huruf hijaiyah, cara membacanya dengan tanda baca hingga keterangan bentuk dari huruf hijaiyah itu sendiri.

6. Aplikasi interaktif ini dapat dijalankan pada komputer dengan spesifikasi yang terjangkau

\section{REFERENCES}

[1] A. Faroqi and B. Maula, "Aplikasi Multimedia Interaktif Pembelajaran Membaca, Menulis, Berhitung (CALISTUNG)," Jurnal ISTEK, vol. VIII, no. 2, pp. 229-245, 2014.

[2] M. Setiawan, A. S. Lumenta and V. Tulenan, "Aplikasi Pembelajaran Interaktif Berbasis Multimedia Untuk Sekolah Dasar (Studi Kasus : SD Negeri I Bitung, Kelas VI)," Jurnal Teknik Elektro dan Komputer, vol. 6, no. 4, pp. 194-205, 2017.

[3] M. Ismail, "Aplikasi Komik Interaktif Cerita Rakyat Jambi Berbasis," Jurnal PROCESSOR, vol. 12, no. 2, pp. 1069-1074, 2017.

[4] E. . N. Sastrakusumah 1, U. Suherman, D. Darmawan and Jamilah, "PENGARUH MEDIA PEMBELAJARAN INTERAKTIF BERBANTUAN APLIKASI ISPRING PRESENTER TERHADAP KEMAMPUAN BERPIKIR KRITIS," Jurnal Teknologi Pendidikan dan Pembelajaran, vol. 3, no. 1, pp. 462-485, 2018.

[5] G. W. Sasmito, "Penerapan Metode Waterfall Pada Desain Sistem Informasi Geografis Industri Kabupaten Tegal," Jurnal Informatika:Jurnal Pengembangan IT (JPIT), vol. 2, no. 1, pp. 6-12, 2017. 